Paving the Way 



\section{Paving the Way}

THE FIRST AMERICAN

WOMEN LAW PROFESSORS

\section{Herma Hill Kay}

Edited by Patricia A. Cain

Foreword by Ruth Bader Ginsburg

Afterword by Melissa Murray

甲

U N IVERSITY OF CALIFORNIA PRES 
University of California Press

Oakland, California

(C) 2021 by Herma Hill Kay Living Trust

Library of Congress Cataloging-in-Publication Data

Names: Kay, Herma Hill, author. | Cain, Patricia A., editor. | Ginsburg,

Ruth Bader, writer of foreword. | Murray, Melissa, writer of afterword.

Title: Paving the way : the first American women law professors / Herma

Hill Kay, edited by Patricia A. Cain ; foreword by Ruth Bader

Ginsburg; afterword by Melissa Murray.

Description: Oakland, California : University of California Press, [2021] | Includes bibliographical references.

Identifiers: LCCN 2020047071 (print) | LCCN 2020047072 (ebook) | ISBN 9780520378957 (cloth) | ISBN 9780520976467 (ebook)

Subjects: LCSH: Women law teachers-United States-Biography.

Classification: LCC KF372 .K39 2021 (print) | LCC KF372 (ebook) |

DDC 340.092/520973-dc23

LC record available at https://lccn.loc.gov/2020047071

LC ebook record available at https://lccn.loc.gov/2020047072

Manufactured in the United States of America

$\begin{array}{lllll}25 & 24 & 23 & 22 & 21\end{array}$

$\begin{array}{llllllllll}10 & 9 & 8 & 7 & 6 & 5 & 4 & 3 & 2 & 1\end{array}$ 